doc. dr. sc. Željko Mateljak

Ekonomski fakultet, Sveučilište u Splitu, Split, Republika Hrvatska zeljko.mateljak@efst.hr

Maja Kraljević, studentica

Ekonomski fakultet, Sveučilište u Splitu, Split, Republika Hrvatska mkralj02@live.efst.hr

\title{
RAZINA IMPLEMENTACIJE NAČELA ORGANIZACIJSKE KULTURE I NJEN UTJECAJ NA MOTIVACIJU ZAPOSLENIKA U DJELATNOSTI OSIGURANJA SPLITSKO-DALMATINSKE ŽUPANIJE
}

Primljen: 30. studeni 2020.

Prihvaćen: 23 . prosinac 2020.

https://doi.org/10.46458/27121097.2020.26.85

\section{Prethodno priopćenje}

\section{Sažetak}

U današnjem, sve složenijem poslovnom okruženju, neophodno je u poduzeću imati visoku razinu implementacije organizacijske kulture s kojim će ono uspješno odgovoriti zahtjevima tržišta. U implementiranju organizacijske kulture najvažniju ulogu ima efikasna provedba temeljnih načela čiji su nositelji zaposlenici što ih čini sve više zadovoljnijim i motiviranijim u ostvarivanju postavljenih ciljeva poduzeća. Stoga je cilj rada identificirati na koji način razina implementacije načela organizacijske kulture utječe na motivaciju zaposlenika u djelatnosti osiguranja Splitsko-dalmatinske županije. Temeljna hipoteze rada ispituje utjecaj više razine implementiranosti načela organizacijske kulture na veću motivaciju zaposlenika u djelatnosti osiguranja Splitsko-dalmatinske županije s obzirom na spol i poziciju zaposlenika te njihovu pripadnost organizacijskim odjelima. Istraživanje provedeno statističkom obradom podataka prikupljenih anketnim upitnikom pokazalo je da postoji različitost utjecaja više razine implementacije načela organizacijske kulture na povećanje motivacije zaposlenika s obzirom na spol $i$ poziciju zaposlenika kod poduzeća u djelatnosti osiguranja Splitsko-dalmatinske, dok prema pripadnosti organizacijskim odjelima ne postoji.

Ključne riječi: organizacijska kultura, motivacija, djelatnost osiguranja, menadžeri, ostali zaposlenici;

JEL: L2 


\section{UVOD}

Pod organizacijskom kulturom se, u najopćenitijem smislu, podrazumijeva ponašanje, vjerovanje i stavovi zaposlenika. U skladu s tim postaje jasno koliko je teško mijenjati kulturu jedne organizacije. Promjena kulture u tom smislu značila bi promjenu stavova i ponašanja svih njezinih zaposlenika, odnosno promjenu čovjeka i njegovu mentalnu transformaciju. S obzirom na činjenicu da većina pojedinaca s otporom prihvaćaju promjene u radnom okruženju koje im se predlažu, te na činjenicu da se u životu rade stvari koje su dio naše rutine i koje nam pružaju sigurnost, jasno je koliko se težak zadatak stavlja pred menadžere poduzeća.

U literaturi postoji jako puno definicija za pojam organizacijske kulture, ali nijedna od tih definicija nije potpuno precizna. No, može se reći da kultura unutar jedne organizacije predstavlja sintezu vjerovanja, djelovanja i načina ponašanja svih pojedinaca u organizaciji. Isto tako, organizacijska kultura se može predstaviti i kao široko rasprostranjen model aktivnosti, interakcija, normi, osjećaja, mišljenja, vjerovanja, pristupa, vrijednosti i procesa u organizaciji (Zdrilić, et. al., 2010., str, 510). Kroz organizacijsku kulturu zaposlenici prihvaćaju određeni sustav vrijednosti koji određuje njihovo ponašanje, način donošenja odluka te se na kraju odražava na uspješnost poslovanja poduzeća. Organizacijska kultura učvršćuje identitet pojedinca u organizaciji. Prihvaćanjem načela organizacijske kulture poduzeća u kojem je zaposlen, pojedinac se obvezuje na poštivanje zadanih normi ponašanja. Na taj način omogućava sebi lakše povezivanje s organizacijom i s kolektivom, razumijevanje interne i eksterne okoline te, samim time, poboljšava društvene odnose.

Kultura je nešto apstraktno, ali sile koje se stvaraju u društvenim i organizacijskim situacijama koje proizlaze iz kulture su vrlo moćne. Ako ne razumijemo djelovanje tih snaga, postajemo njihovom žrtvom. Kulturne sile su moćne upravo zato što djeluju izvan naše svijesti. Čovjek ih, iako nesvjestan, mora razumjeti, ne samo zbog njihove moći i snage, nego i zbog toga što se pomoću njih mogu objasniti mnoga naša zagonetna i frustrirajuća iskustva u društvenom i organizacijskom životu. Najvažnije od svega je razumijevanje kulturalnih sila koje nam omogućavaju bolje razumijevanje nas samih (Schein, 2010., str. 7).

Kultura je, najšire shvaćeno, sveukupno postignuće ljudskog roda od prapovijesti do naših dana i obuhvaća sva materijalna i duhovna dobra. Kultura se može promatrati i u užem smislu, a tada se pod tim pojmom razumijeva čitav niz različitih pojmova i kategorija, od kojih su navedene neke (Žugaj, et. al., 2004., str. 18):

- lijepo, pristojno i društveno prihvatljivo ponašanje pojedinca,

- ponašanje društvene skupine, 
- vremensko razdoblje ili epoha ujednačenih stilskih karakteristika (npr. antička kultura), ali i

- način života i ponašanje pojedinih naroda ili skupina naroda.

Kultura je relativno trajan i specifičan sustav oblika ponašanja, prihvaćenih vrijednosti i uvjerenja, normi i običaja koji određuje organizacijsko ponašanje, mišljenje i usmjerava sve aktivnosti pripadnika jedne organizacije. Njome se izražava specifičan način ponašanja i stil života organizacije i grupa unutar nje. Najopćenitije, organizacijska kultura predstavlja osobnost, odnosno karakter poduzeća (Robbins, 1996., str. 254).

Organizacijska kultura predstavlja svojevrstan izraz, ali i osnovu na kojoj se razvija određena organizacijska struktura, strategija i specifičan stil ponašanja po kojem se organizacija razlikuje i prepoznaje u poslovnom svijetu. Ona predstavlja svojevrstan regulator i katalizator ponašanja, generira određenu atmosferu i odnose unutar organizacije. Jaka organizacijska kultura je osnovna pretpostavka uspjeha i razvoja poduzeća u suvremenim i nestabilnim uvjetima. Međutim, za uspješnost poduzeća nije dovoljno samo postojanje jake organizacijske kulture, nego je neophodna i njena kompatibilnost sa strategijom poduzeća. Organizacijska kultura je izvor snage i slabosti poduzeća, a njeno mijenjanje često je osnovna pretpostavka uspjeha i razvoja (Bahtijarević-Šiber, 1991., str. 29).

Kako bi organizacijska kultura bila izvor snage za poduzeće, a ne izvor njegove slabosti, neophodno je da ona bude prihvaćena od svih zaposlenika, počevši od vrhovnog menadžmenta prema nižim hijerarhijskim razinama. Mnoga poduzeća se nađu u situaciji da je nužno mijenjati organizacijsku kulturu za njihov opstanak, a promjena organizacijske kulture nije ništa drugo nego promjena postojećih stavova i ponašanja ljudi unutar poduzeća. Pri promjeni kulture ne smije se zanemariti početni otpor promjenama koji je neizbježan kada zaposlenicima postane jasno koliko su te promjene duboke i kako utječu na tradicionalan način djelovanja. Promjena kulture jedan je od najvećih izazova s kojima se organizacija susreće, stoga je za te korijenite promjene neophodna podrška vrhovnog menadžmenta. Iz ovoga slijedi da je ponekad, za promjenu organizacijske kulture, nužno promijeniti vrhovni menadžment (Zdrilić, et. al., 2010., str. 510).

Kultura se može tretirati i kao niz osebujnih svojstava pojedinačne organizacije. Dok su neke od njih dinamične i moderne, okrenute stvaralaštvu, inovacijama i poduzetništvu, druge su tradicionalne, trome i krute, sporo se mijenjaju i teško prihvaćaju promjene. Za menadžera je poznavanje kulture iznimno bitno, a mogućnost prilagođavanja kulturi za poduzeća je neophodan čimbenik opstanka unutar organizacije. Ako se dobro upoznaju elementi organizacijske kulture i ako 
se uspiju uskladiti s ciljevima organizacije, tada će biti stvoreni glavni preduvjeti za uspješno djelovanje organizacije. Osobne vrijednosti, izražene u uvjerenjima i stavovima zaposlenih, utječu na sve aspekte menadžmenta i definiraju elemente po kojima se jedna organizacija razlikuje od druge. Zato je elemente organizacijske kulture potrebno preciznije definirati (Žugaj, et. al., 2004., str. 20). Različiti autori navode različite elemente organizacijske kulture. Prema Žugaju i Cinguli (1992., str. 210) postoje tri važna elementa organizacijske kulture, a to su:

- Organizacijske vrijednosti koje predstavljaju sve ono što je dobro za organizaciju. U tom smislu, naglasak se prvenstveno stavlja na međusobno povjerenje i poštovanje pripadnika organizacije, zadovoljstvo vanjskih suradnika i poslovnih partnera, financijsku stabilnost organizacije, izražen timski duh kod zaposlenika. Organizacijske vrijednosti su zapravo strategijski cilj poduzeća i ono čemu svako poduzeće treba težiti (Žugaju i Cinguli, 1992., str. 210).

- Organizacijska klima, kao složeni skup nematerijalnih resursa organizacije, jedan je od oblika socijalne klime, jer je organizacija viši oblik socijalne grupe. Budući da organizacijska klima nastaje u interakciji karakteristika ličnosti članova organizacije i zahtjeva posla, može se definirati i kao misli i osjećaji djelatnika o različitim aspektima posla. Iako nema sveopće prihvaćene definicije organizacijske klime, klima je nešto što organizacije imaju, a može se definirati i kao „naučeni odgovori na grupne probleme vezani uz opstanak i unutarnju jedinstvenost" (Bogdanović, 2003., str. 830). Pojednostavljeno, organizacijska klima je radna atmosfera koja utječe na motivaciju zaposlenih, a njena uloga je da svaki pripadnik organizacije bude zadovoljan i motiviran.

- Menadžerski stil koji odražava ponašanje menadžera u poduzeću. Karakteristike menadžera kao osobe najviše utječu na njegovo ponašanje u poduzeću. Tako se menadžersko ponašanje može promatrati kao autoritativni stil, demokratski stil i „laissez-fair“ stil (Dulčić i Vrdoljak-Raguž, 2007., str. 711). Kod autoritativnog stila komunikacija između menadžera i zaposlenika se odvija isključivo odozgo prema dolje, a kod zaposlenika se javlja strahopoštovanje prema takvom vođi (Kurtić i Kulović., 2011., str. 17). Demokratski stil podrazumijeva međusobnu komunikaciju između zaposlenika i menadžera, opušteniju radnu atmosferu i zajedničko donošenje odluka (Tudor, et, al., 2009., str. 47). Laissez-fair stil je oblik vodstva kod kojeg menadžer izbjegava moć i odgovornost, zaposlenici imaju potpunu slobodu odlučivanja i komunikacija se odvija isključivo među zaposlenicima (Tudor, et, al., 2009., str. 47). 
Druga skupina autora smatra da su ključni elementi organizacijske kulture koji dovode do uspješnosti poduzeća sljedeći (Štok - Meško, et. al., 2010., str. 306):

- Kvalitetna komunikacija omogućuje bolje međusobno razumijevanje kao i postizanje zajedničkih rješenja. Temelj uspjeha timskog rada je upravo kvalitetna komunikacija među članovima tima. Ona ima pozitivan utjecaj na svakog člana pojedinačno, što im u konačnici omogućuje brže i efikasnije rješenje određenih pitanja koja ne bi mogli riješiti kao pojedinci (Štok - Meško, et. al., 2010., str. 306).

- Dobri međuljudski odnosi pripadnika jedne organizacije proizlaze iz kvalitetne komunikacije. Smatra se da su međuljudski odnosi odraz radne atmosfere i da se na taj način poboljšava emocionalno stanje zaposlenika (Štok - Meško, et. al., 2010., str. 307).

- Motivacija je osnovni pokretač zaposlenika. Bez motivacije nijedan zaposlenik neće biti u stanju dugoročno opstati u poduzeću. Zbog toga ova skupina autora smatra da bi upravo menadžeri trebali stvoriti takvo radno okruženje u kojem će zaposlenici biti motivirani i u kojem će moći bez straha izražavati svoja mišljenja, zahtjeve i očekivanja (Štok - Meško, et. al., 2010., str. 308).

- Prema spomenutim autorima, novac je najveći, ali ne i jedini faktor stimulacije za zaposlenika. U tom smislu, velik naglasak se stavlja na edukacije zaposlenih, unapređenja, kvalitetno radno okruženje pa čak i dodatnu odgovornost.

Iz navedenog se može zaključiti da su svi ovi elementi organizacijske kulture povezani. Kvalitetno radno okruženje počinje upravo od dobre i kvalitetne međusobne komunikacije zaposlenika, a upravo takva komunikacija stvara dobre međuljudske odnose i dobru radnu atmosferu.

Prema Bahtijarević-Šiber i ostalima (1991., str. 118-123), treća podjela elemenata organizacijske kulture dijeli elemente na:

- Vrijednosti u ovom slučaju predstavljaju prioritete koji su temelj za razvoj organizacije. To, npr. može uključivati orijentaciju poduzeća na zadovoljstvo kupaca i klijenata, poticanje zaposlenih na inovacije i kreativna mišljenja i sl.

- Norme, koje mogu biti pisane i nepisane, predstavljaju način odnosno postupak kojim se nešto želi postići. Normama se određuje kakvo se ponašanje očekuje od zaposlenika, a kakvo ponašanje ni u kojem slučaju nije prihvatljivo. 
- Stavovi i uvjerenja, najjednostavnije rečeno, odražavaju sustav uvjerenja unutar organizacije koji se manifestira kroz osnovne ideale i načela ponašanja organizacije.

- Običaji i rituali se odnose na ustaljene i uobičajene oblike ponašanja pripadnika organizacije. Njihovim jačanjem i naglašavanjem se povećava identifikacija zaposlenika s organizacijom i stvaraju se kvalitetni međuljudski odnosi.

- Jezik je znak određenog socijalnog statusa djelatnika u organizaciji. On je blizak pratitelj i odraz svega onoga što se događa u organizaciji. Njime se uvjerava, naređuje i emocionalno rasterećuje. Komuniciranjem neka osoba ili organizacija izražava svoj identitet. Temeljem svog verbalnog i neverbalnog načina komuniciranja organizacija i pojedinac izražava svoju razinu kulture.

- Simboli su „znakovi prepoznavanja“ organizacije, odnosno, predstavljaju vanjske vizualne znakove organizacije.

Svi prethodno navedeni elementi predstavljaju osobnost jednog poduzeća. tj. organizacije. Isto kao što unutar jedne obitelji postoje određena pravila ponašanja, običaji, tradicije, vjerovanja i sustav vrijednosti, tako i svaka organizacija ima (više ili manje) zastupljene navedene elemente. Poznavanje ovih elemenata, njihovo prihvaćanje i prilagođavanje njima predstavlja determinantu za rast poduzeća i izdvajanje poduzeća od konkurencije.

S druge strane, menadžeri su onaj važan faktor poduzeća koji je zadužen za širenje organizacijske kulture na sve dijelove poduzeća. Također, su zaduženi za motiviranje svojih zaposlenika. No, da bi obavljanje tih zadataka bilo uspješno menadžeri i sami moraju imati visoku razinu motivacije. Kvalitetan menadžer može biti pokretač rasta poslovanja poduzeća, isto kao što i nekvalitetan menadžer može biti ograničenje rastu poduzeća. Pored stručnosti u obavljanju posla za koji je zadužen, jedan kvalitetan menadžer svakako mora posjedovati socijalnu osviještenost i određene psihološke vještine kako bi mogao ,pročitati“ i razumjeti potrebe svojih zaposlenika. Točnije, kvalitetan menadžer bi trebao znati što je ono što motivira i pokreće svakog njegovog zaposlenika.

Suština motivacije je objasniti zašto pojedinac odabire pojedini obrazac ponašanja između različitih mogućnosti. Da bi se došlo do odgovora potrebno je provesti analizu ciljeva koje pojedinac postavlja pred sebe odnosno zašto ljudi rade. Dok najveći broj radi zbog osiguranja egzistencije, drugi rade zbog ispunjavanja osobnih ciljeva, ostvarivanja društvenog položaja, osobnog zadovoljstva, usavršavanja, povećanja materijalnog bogatstva, itd. Kvalitetno obavljanje posla ovisi o mnogim psihološkim faktorima. Motivacija nije samo psihološki nego i 
sociološki te ekonomski faktor rada, radnog ponašanja, razvoja i unapređivanja razvojnih snaga, ali i pretpostavka zainteresiranosti svih subjekata da se racionalno ponašaju u svom poslu uz maksimalan doprinos i razvoj.

Da bi organizacijska kultura bila efikasno implementirana u poduzeću, orijentacija menadžera mora biti da svojim ponašanjem budu primjer svim članovima organizacije. Svojim pozitivnim utjecajem na zaposlenike menadžeri moraju biti u mogućnosti potaknuti ih da probiju granice svoje „komfort zone“, da oblikuju pojedince u organizaciji te da u njima probude volju i želju za promjenom, učenjem i prihvaćanjem onoga na što možda i nisu navikli. Upravljanje ljudskim potencijalima odnosno motiviranje ljudi za usmjeravanje njihovih ukupnih stručnih, intelektualnih i kreativnih potencijala u pravcu ostvarivanja organizacijskih ciljeva i povećanja njenih razvojnih potencijala, postaje najvažniji zadatak modernog menadžmenta i temeljna pretpostavka uspješnosti suvremenih organizacija (Bahtijarević-Šiber, 1996., str. 127). Prije nego što se menadžer odluči na provođenje radikalne organizacijske promjene, treba provesti analizu postojećeg stanja organizacijske kulture. Ukoliko ustanovi da je postojeća organizacijska kultura nefunkcionalna u smislu izgradnje pozitivnog stava prema promjenama, postizanju organizacijske predanosti i povjerenja, zadatak je menadžera da kroz prizmu organizacijske klime djeluje na izmjenu organizacijskih vrijednosti (Belak i Ušljebrka, 2014., str. 95).

Uz organizacijsku kulturu, motivacijski sustav organizacije mora biti oblikovan tako da zadovolji potrebe i želje većeg broja zaposlenika te da bude usmjeren na podizanje individualne radne uspješnosti stvarajući i nagrađujući poželjne oblike ponašanja. Primjeren i djelotvoran motivacijski sustav uključuje i više različitih oblika nagrađivanja, kao i pravednost pri raspodjeli nagrada zaposlenicima (Brnad, et. al., 2016., str. 109). Motivacija se definira na više načina. U psihologiji se najčešće definira kao" ponašanje usmjereno prema nekom cilju koji pobuđuje potrebe izazvane u čovjeku odnosno razlog ponašanja koje je zadovoljenje potreba“. Ona u biti označava emociju ili potrebu čovjeka koje ga potiču na akciju (Marušić, 2006. str. 318). Stoga se postavlja pitanje zašto je motivacija uopće važna za poslovanje tvrtke. Motivacija ima izravne i neizravne utjecaje, te na taj način bitno utječe na uspješnost obavljanja radnih zadataka, poboljšanje radnog učinka zaposlenika, produktivnost i efikasnost (Varga, 2011., 153-154). Motivacija je faktor koji ljude potiče na određene obrasce ponašanja. Sukladno tome, svaka organizacija koja se želi istaknuti ili uopće ostati na tržištu, mora uložiti značajne napore povećanju motivacije svojih zaposlenika.

Iz prethodno navedenog može se zaključiti da jaka i efikasna organizacijska kultura u poduzeću predstavlja ključan preduvjet za ostvarenje vizije, misije i ciljeva poduzeća. U tom smislu, pred menadžere, a i ostale zaposlenike, postavlja 
se zadatak da sustavno i temeljito pristupe podizanju razine implementacije temeljnih načela organizacijske kulture. Stoga je predmet ovog istraživanja analiza utjecaja razine implementiranosti načela organizacijske kulture na motivaciju zaposlenika u djelatnosti osiguranja Splitsko-dalmatinske županije. Problem ovog istraživanja je u kojoj su mjeri zaposlenici anketiranih poduzeća upoznati s načelima organizacijske kulture te koje su eventualne posljedice nepoštivanja istih načela. Uz to, cilj istraživanja je identificiranje razine implementiranosti temeljnih načela organizacijske kulture i u kojoj mjeri oni utječu na motivaciju zaposlenika u djelatnosti osiguranja na području Splitsko-dalmatinske županije. Temeljem toga, u ovom radu postavljena je temeljna istraživačka hipoteza (H1.) koja glasi: Viša razina implementiranosti načela organizacijske kulture različito utječe na povećanje motivacije zaposlenika u djelatnosti osiguranja Splitsko-dalmatinske županije. Temeljna istraživačka hipoteza rada ispitat će se pomoću tri pomoćne hipoteze, i to:

H.1.1. Viša razina implementiranosti načela organizacijske kulture različito utječe na povećanje motivacije između menadžera i ostalih zaposlenika u djelatnosti osiguranja Splitsko-dalmatinske županije.

U testiranju ove hipoteze polazi se od pretpostavke da viša razina implementiranosti načela organizacijske kulture manje utječe na povećanje motivacije menadžera nego kod ostalih zaposlenika u djelatnosti osiguranja Splitsko-dalmatinske županije.

H.1.2. Viša razina implementiranosti načela organizacijske kulture različito utječe na povećanje motivacije zaposlenika između organizacijskih odjela u djelatnosti osiguranja Splitsko-dalmatinske županije.

U testiranju ove hipoteze polazi se od pretpostavke da viša razina implementiranosti načela organizacijske kulture manje utječe na povećanje motivacije zaposlenika u odjelu prodaje i pribave nego u ostalim odjelima u djelatnosti osiguranja Splitsko-dalmatinske županije.

H1.3. Viša razina implementiranosti načela organizacijske kulture različito utječe na povećanje motivacije muškaraca $i$ žena zaposlenih u djelatnosti osiguranja Splitsko-dalmatinske županije.

U testiranju ove hipoteze polazi se od pretpostavke da viša razina implementiranosti načela organizacijske strukture više utječe na povećanje motivacije muškaraca nego žena zaposlenih u djelatnosti osiguranja Splitsko-dalmatinske županije. 
Za testiranje temeljne i pomoćnih istraživačkih hipoteza rada korištene su standardne metode deskriptivne statistike i metoda korelacije, točnije Spearmanov koeficijent korelacije o utjecaju razine implementiranosti načela organizacijske kulture na motivaciju zaposlenika u djelatnosti osiguranja Splitsko-dalmatinske županije. Također je bitno naglasiti da su se prikupljeni podaci obradili uz pomoć statističkih alata IBM SPSS Statistics 25. Istraživanje je provedeno nad ukupno 188 zaposlenika u djelatnosti osiguranja Splitsko dalmatinske županije.

\section{PRETHODNA ISTRAŽIVANJA}

O povezanosti organizacijske kulture i motivacije zaposlenika što se odražava na poslovanje poduzeća postoje brojna istraživanja. Tako su Denison i Mishura (1995., str. 204) proveli istraživanje na ovu temu u kojem su istaknuli četiri bitna obilježja organizacijske kulture koja su bila vezana za učinkovitost $i$ uspješnost različitih poduzeća, i to:

- uključenost (participacija) zaposlenika koja uključuje opunomoćenje zaposlenika, timsku orijentaciju i razvoj sposobnosti zaposlenih,

- konzistentnost koja se odnosi na temeljne vrijednosti, suglasnost i koordiniranu integraciju,

- adaptabilnost koja se odnosi na stvaranje promjena, usmjerenost prema potrošačima i organizacijsko učenje, $i$

- misiju organizacije koja predstavlja strateško usmjerenje, ciljeve i viziju organizacije.

Autori su došli do zaključka da svako od četiri obilježja kulture pokazuje signifikantnu pozitivnu vezu s velikim brojem objektivnih i subjektivnih mjerila organizacijske uspješnosti i učinkovitosti. Posebno su mjereni pokazatelji kao što su povrat na ukupnu imovinu (engl. Return On Assets, ROA), povrat na investirano (engl. Return On Investment, ROI) i povrat na prodaju (engl. Return On Sale, ROS), razvoj i kvaliteta proizvoda, rast prodaje, tržišni udio i zadovoljstvo zaposlenika. Rezultati provedenog istraživanja pokazali su da:

- se misija i konzistentnost najviše odražavaju na financijske pokazatelje (pokazatelje profitabilnosti) kao što su ROA, ROI i ROS, tj. u slučaju stabilne organizacije ovi pokazatelji imaju visoke vrijednosti,

- su participacija zaposlenika i adaptabilnost obilježja fleksibilne organizacije koja omogućuju visoke razine proizvodnje i uslužne inovativnosti (kreativnosti), kao i brzi odgovor organizacije na promjenjive potrebe kupaca i zaposlenika, 
- konzistentnost i participacija zaposlenika (interno usmjerenje organizacije) najsnažnije utječu na kvalitetu, zadovoljstvo zaposlenika i ROI, odnosno interno usmjerenje organizacije koje je vezano za visoku razinu kvalitete proizvoda, dobro iskorištenje resursa i visoku razinu zadovoljstva njezinih zaposlenika,

- se adaptabilnost i misija (eksterno usmjerenje organizacije), kao posebno izražena obilježja, odražavaju u neprestano rastućem povećanju obujma prodaje i tržišnog udjela.

Prema Uzzoni (2013., str. 202) provedeno je istraživanje o utjecaju motivacije na učinak zaposlenika na primjeru Credit West Banke na Cipru. Točnije, istraživanje je obuhvatilo 134 zaposlenika na temu faktora motivacije. Faktori motivacije razdvojeni su na vanjske i unutarnje. U ovom istraživanju kao vanjski faktori motivacije korišteni su novac i novčane nagrade, viša pozicija, te veće odgovornosti. S druge strane, korišteni su i unutarnji (psihološki) faktori motivacije poput priznanja (od strane nadređenih), prilika za napredovanje, autoritet, autonomija, izazovnost posla, sigurnost posla, titula, te dodijeljena odgovornost. Većina ispitanika, koji su sudjelovali u ovom istraživanju, su se izjasnili da bi za svoj rad radije bili nagrađeni višom pozicijom. Također iz prikupljenih podataka došlo se do rezultata da se većina ispitanika slaže s tim da su priznanje i autoritet dvije najvažnije nenovčane varijable motivacije, a usko ih slijede prilika za napredovanjem, autonomija, sigurnost posla, odgovornost, titula i izazovnost posla. Rezultati provedenog istraživanja također su pokazali da:

- 50\% ispitanika za svoj rad želi biti nagrađeno višom pozicijom,

- $24 \%$ ispitanika smatra da je svaki vanjski faktor motivacije jednako važan,

- većina ispitanika se slaže s tim da su priznanje i autoritet dvije najvažnije nenovčane varijable motivacije,

- većina ispitanika se slaže da je izazovnost posla na zadnjem mjestu kad je riječ o nenovčanim faktorima motivacije.

Nadalje, prema Danishu (2010., str. 162) također je provedeno slično istraživanje 2010. godine o utjecaju nagrada i priznanja na zadovoljstvo poslom i motivaciju kod zaposlenika u sektorima financija, telekomunikacije, obrazovanja, zdravstva te ostalim privatnim i javnim sektorima u Pakistanu na uzorku od 220 ispitanika. U istraživanje su uključene varijable poput mogućnosti napredovanja, mogućnosti samostalnog rada, poštivanja radnih postupaka (pravila i propisi koji se moraju poštivati na radnom mjestu), priznanja, odnosa sa suradnicima, zadovoljstva kompenzacijama, sigurnosti posla, zadovoljstva s nadređenima, mogućnosti osobnog razvoja, te osjećaja uspjeha. Rezultati istraživanja pokazali su da: 
- mogućnost promaknuća, mogućnost samostalnog rada, radni postupci, odnos sa suradnicima i osjećaj uspjeha imaju statistički značajan, pozitivan i jak utjecaj na zadovoljstvo i motivaciju zaposlenih,

- statistički gledano, najveći utjecaj na motivaciju i zadovoljstvo zaposlenih imaju radni postupci i zadovoljstvo kompenzacijama,

- pozitivan i srednje jak utjecaj na motivaciju i zadovoljstvo zaposlenih ima samostalan rad, mogućnost promaknuća i osjećaj uspjeha,

Cucu-Ciuhan i Guita-Alexandru (2014., str. 450-452) su proveli istraživanje o odnosu organizacijske kulture i radne motivacije među akademskim osobljem na javnim sveučilištima u Rumunjskoj. Istraživanje je provedeno među 102 nastavnika sa sveučilišta. Rezultati istraživanja su pokazali da postoji statistički značajna povezanosti između željene organizacijske kulture i motivacije na radnom mjestu $(\mathrm{p}=0,000)$ i između postojeće organizacijske kulture i motivacije na radnom mjestu $(\mathrm{p}<0,001)$.

Copuš i ostali (2019., str. 362-366) u također proveli istraživanje o utjecaju organizacijske kulture na motivacijski potencijal kod proizvodnih poduzeća u Slovačkoj koristeći metodologiju 9 faktora. Motivacijski potencijal radnika istražili su koristeći 9 faktora motivacije, i to identifikaciju, pravednost, ravnopravnost, konsenzus, način motivacije, racionalnost, razvoj, dinamiku rada u grupi i samopouzdanje. Rezultati istraživanja su pokazali da je organizacijska kultura kod proizvodnih radnika uzrokuje manji motivacijski potencijal nego kod neproizvodnih radnika (-0,09 naspram 0,29 i -0,04 naspram 0,50$)$.

Nadalje, o utjecaju organizacijske kulture na motivaciju zaposlenika provedeno je istraživanje od strane Panagiotisa i ostalih (2014., str. 419-422) u javnom sektoru, točnije u gradu Zografou u Grčkoj nad 475 administrativnih radnika. Stopa povrata je bila 14,2\%. Organizacijska kultura je mjerena faktorima kao što su dominantne karakteristike organizacije, vodstvo, organizacijska dinamičnost, strateški značaj, kriteriji uspjeha i stil menadžmenta. Rezultati istraživanja su pokazali da je dominantan hijerarhijski tip organizacijske kulture, dok iza slijedi klanski tip. S druge strane, istraživanje je također pokazalo da je hijerarhijska organizacijska kultura stvorila nizak stupanj motivacije radnika (vrijednost između 2,06 i 2,875 od 5 stupnjeva ocjenjivanja motivacije radnika). Ispitanici su izrazili nezadovoljstvo hijerarhijskim tipom kulture te su predložili da bi bila bolja organizacijska kultura klana i fleksibilna organizacijska kulture na radnom mjestu. Kada se metodom korelacije usporede sva tri tipa organizacijske kulture s motivacijom radnika dobiveni rezultati pokazuju da je odnos između hijerarhijske organizacijske kulture i motivacije radnika slab i statistički negativan $(\mathrm{r}=-0,341 ; \mathrm{p}=0,015 ; \mathrm{p}<0,05)$, između organizacijske kulture klana i motivacije 
srednje jakosti i statistički pozitivan $(r=0,434 ; \mathrm{p}=0,002 ; \mathrm{p}<0,005)$ te između fleksibilne organizacijske kulture i motivacije slab, negativan i statistički neznačajan $(\mathrm{r}=-0,073 ; \mathrm{p}=0,615 ; \mathrm{p}<0,005)$.

\section{INTERPRETACIJA REZULATA ISTRAŽIVANJA}

\subsection{Metodologija istraživanja}

Primarni podaci prikupljeni su anketnim upitnikom koji je podijeljen na tri dijela. U prvom dijelu sadržane su osnovne informacije o ispitanicima, odnosno opći podaci. Drugi dio sadrži temeljna načela organizacijske kulture, a treći dio faktore vezane uz motivaciju ispitanika na radnom mjestu. Tvrdnje u drugom i trećem dijelu upitnika vrednovane su skalom od 5 stupnjeva, i to 1 - uopće se ne slažem, 2 - djelomično se ne slažem, 3 - niti se slažem niti se ne slažem, 4 - djelomično se slažem, 5 - u potpunosti se slažem. Anketni upitnik ukupno su ispunila 52 ispitanika od njih mogućih 188 ispitanika što čini stopu povrata od 27,66\%. Vrijeme provedbe istraživanja je bilo od 29. kolovoza do 9. rujna 2019. godine.

Prikupljeni podaci, su uz pomoć programskih alata, pripremljeni za daljnju obradu te su obrađeni statističkim alatom IBM SPSS Statistics 25. U statističkoj obradi podataka korištene su standardne metode deskriptivne statistike i metoda korelacije s ciljem utvrđivanja povezanosti između istraživačkih varijabli. Pouzdanost istraživanja između razine implementacije načela organizacijske kulture i motivacije zaposlenika određena je metodom unutarnje konzistencije i izražena Cronbach-ovim alfa koeficijentom od 0,867. Potvrđena je zadovoljavajuća pouzdanost upitnika s koeficijentima koji prelaze 0,70. Razina pouzdanosti, tj. statističke značajnosti koja se koristila pri obradi podataka je 5\% $(\mathrm{p}<0,05)$.

\subsection{Deskriptivna analiza rezultata istraživanja}

U ovom dijelu rada najprije će se primjenom metoda deskriptivne statistike prikazati osnovni podaci o ispitanicima. Točnije, u sljedećim tablicama prikazat će se ispitanici prema četiri karakteristike, i to: spolu, dobi, odjelu u kojem rade i radnom iskustvu. $U$ tablici 1. prikazani su ispitanici prema spolu. 
Tablica 1. Ispitanici prema spolu

\begin{tabular}{|c|c|c|c|c|}
\hline Spol & Frekvencija & Postotak & Valjani postotak & $\begin{array}{c}\text { Kumulativni } \\
\text { postotak }\end{array}$ \\
\hline Muški & 28 & 53.8 & 53.8 & 53.8 \\
\hline Ženski & 24 & 46.2 & 46.2 & 100.0 \\
\hline Ukupno & $\mathbf{5 2}$ & $\mathbf{1 0 0 . 0}$ & $\mathbf{1 0 0 . 0}$ & - \\
\hline
\end{tabular}

Izvor: Izrada autora prema SPSS programu

Iz tablice 1. vidljivo je da je u uzorku od 52 ispitanika više ispitanika muškog spola, točnije njih 28. Preostale 24 osobe su ženskog spola. Odnosno, od 52 ispitanika njih 53,8\% su muškarci, a 46,2\% su žene. Nadalje, u tablici 2. prikazane su ispitanici prema dobi.

Tablica 2. Ispitanici prema dobi

\begin{tabular}{|c|c|c|c|c|}
\hline Dob ispitanika & Frekvencija & Postotak & $\begin{array}{c}\text { Valjani } \\
\text { postotak }\end{array}$ & $\begin{array}{c}\text { Kumulativni } \\
\text { postotak }\end{array}$ \\
\hline $20-30$ godina & 17 & 32.7 & 32.7 & 32.7 \\
\hline $31-40$ & 18 & 34.6 & 34.6 & 67.3 \\
\hline $41-50$ & 12 & 23.1 & 23.1 & 90.4 \\
\hline $51-60$ & 5 & 9.6 & 9.6 & 100.0 \\
\hline Total & 52 & $100.0 \%$ & 100.0 & - \\
\hline
\end{tabular}

Izvor: Izrada autora prema SPSS programu

Tablica 2. prikazuje da najveći broj ispitanika pripada dobnoj skupini od 31-40 godina, točnije njih 18 (34,6\%), zatim slijede ispitanici koji pripadaju dobnoj skupini od 20-30 godina, njih 17 (32,7\%). 12 ispitanika (23,1\%) pripada dobnoj skupni od 41-50 godina, dok njih 5 pripada dobnoj skupini od 51-60 godina $(9,6 \%)$. U tablici 3. prikazani su ispitanici prema odjelu u kojem rade u poduzeću.

Iz tablice 3. vidi se da najveći broj ispitanika radi u odjelu prodaje i pribave, točnije njih $20(38,5 \%)$, zatim slijede ispitanici koji rade u odjelu računovodstva $i$ financija, njih $16(30,8 \%) .15$ ispitanika ( 8,8\%) radi u ostalim odjelima, a samo 1 ispitanik $(1,9 \%)$ radi na odjelu štete.

Tablica 3. Ispitanici prema odjelu u kojem rade u poduzeću

\begin{tabular}{|c|c|c|c|c|}
\hline Odjel & Frekvencija & Postotak & $\begin{array}{c}\text { Valjani } \\
\text { postotak }\end{array}$ & $\begin{array}{c}\text { Kumulativni } \\
\text { postotak }\end{array}$ \\
\hline prodaja i nabava & 20 & 38.5 & 38.5 & 38.5 \\
\hline računovodstvo i financije & 16 & 30.8 & 30.8 & 69.2 \\
\hline štete & 1 & 1.9 & 1.9 & 71.2 \\
\hline ostali odjeli & 15 & 28.8 & 28.8 & 100.0 \\
\hline Total & $\mathbf{5 2}$ & $\mathbf{1 0 0 . 0}$ & $\mathbf{1 0 0 . 0}$ & - \\
\hline
\end{tabular}

Izvor: Izrada autora prema SPSS programu 
Radno iskustvo, kao četvrta karakteristike ispitanika, prikazana je u tablici 4.

Tablica 4. Frekvencije ispitanika prema radnom iskustvu u djelatnosti osiguranja

\begin{tabular}{|c|c|c|c|c|}
\hline Radno iskustvo & Frekvencija & Postotak & $\begin{array}{c}\text { Valjani } \\
\text { postotak }\end{array}$ & $\begin{array}{c}\text { Kumulativni } \\
\text { postotak }\end{array}$ \\
\hline do 5 godina & 18 & 34.6 & 34.6 & 34.6 \\
\hline 6 - 10 godina & 16 & 30.8 & 30.8 & 65.4 \\
\hline $11-15$ godina & 10 & 19.2 & 19.2 & 84.6 \\
\hline $16-20$ godina & 4 & 7.7 & 7.7 & 92.3 \\
\hline više od 20 godina & 4 & 7.7 & 7.7 & 100.0 \\
\hline Total & $\mathbf{5 2}$ & $\mathbf{1 0 0 . 0}$ & $\mathbf{1 0 0 . 0}$ & - \\
\hline
\end{tabular}

Izvor: Izrada autora prema SPSS programu

Kao što prikazuje tablica 4. najveći broj ispitanika ima do 5 godina radnog iskustva u djelatnosti osiguranja, njih 18 (34,6\%), zatim slijede ispitanici sa od 6-10 godina iskustva, njih $16(30,8 \%) .10$ ispitanika $(19,2 \%)$ ima od 11-15 godina radnog iskustva, 4 ispitanika (7,7\%) imaju od 16-20 godina iskustva kao i 4 ispitanika s više od 20 godina radnog iskustva u djelatnosti osiguranja.

U nastavku rada se metodama deskriptivne statistike analiziraju načela organizacijske kulture kojima se identificira njihova razina implementiranosti. U dijelu anketnog upitnika koji se odnosi na organizacijsku kulturu sadržana su 23 načela. Za svako navedeno načelo ispitanici su se trebali izjasniti u kojem se stupnju slažu s istim koristeći skalu od 1 do 5 . Na temelju iste skale određuje se niža i viša razina implementiranosti. Svako načelo koje ima prosječnu ocjenu od 1 do 2,5 pokazuje nižu razinu implementiranosti, dok svako načelo koje ima prosječnu ocjenu od 2,5 do 5 pokazuje visoku razinu implementiranosti. Isti način određivanja ukupne razine implementiranosti temeljnih načela organizacijske kulture primjenjuje se kod anketiranih poduzeća. Stoga je u tablici 5. prikazana aritmetička sredina odnosno prosječna ocjena svakog od 23 načela putem kojih se identificira razina implementiranosti, kao i ukupna razina implementiranosti temeljnih načela organizacijske kulture kod anketiranih poduzeća dobivena metodom aritmetičke sredine aritmetičkih sredina. 
Tablica 5. Deskriptivna statistika načela organizacijske kulture

\begin{tabular}{|c|c|c|c|c|c|c|c|c|}
\hline \multirow[b]{2}{*}{ Načelo } & \multicolumn{2}{|c|}{ Odgovorilo } & \multirow{2}{*}{$\begin{array}{c}\text { Ar. } \\
\text { sredina }\end{array}$} & \multirow{2}{*}{$\begin{array}{l}\text { Medi- } \\
\text { jan }\end{array}$} & \multirow[b]{2}{*}{ Mod } & \multirow{2}{*}{$\begin{array}{l}\text { St. } \\
\text { dev. }\end{array}$} & \multirow[b]{2}{*}{ Min } & \multirow[b]{2}{*}{ Max } \\
\hline & Valjano & $\begin{array}{c}\text { Nedo- } \\
\text { staje }\end{array}$ & & & & & & \\
\hline $\begin{array}{l}\text { Mogućnost obavlja- } \\
\text { nja složenijih radnih } \\
\text { zadataka }\end{array}$ & 52 & 0 & 2.29 & 2 & 2 & 1.177 & 1 & 5 \\
\hline $\begin{array}{l}\text { Zaposlenici često } \\
\text { primaju kritike za } \\
\text { svoj rad. }\end{array}$ & 52 & 0 & 3.02 & 3 & 4 & 1.019 & 1 & 5 \\
\hline \begin{tabular}{|l|} 
Učestali timski rad \\
\end{tabular} & 52 & 0 & 3.06 & 3 & 4 & 1.243 & 1 & 5 \\
\hline $\begin{array}{c}\text { Loše obavljeni rad- } \\
\text { ni zadaci - smanje- } \\
\text { nje plaće }\end{array}$ & 52 & 0 & 3.06 & 3 & 3 & 1.211 & 1 & 5 \\
\hline $\begin{array}{c}\text { Druženje s kolega- } \\
\text { ma izvan radnog } \\
\text { vremena }\end{array}$ & 52 & 0 & 3.13 & 3 & 3 & 1.067 & 1 & 5 \\
\hline \begin{tabular}{|c} 
Učestalo pohađanje \\
edukacijskih semi- \\
nare i druge moguć- \\
nosti učenja.
\end{tabular} & 52 & 0 & 3.69 & 4 & 4 & 0.961 & 1 & 5 \\
\hline $\begin{array}{l}\text { Postojanost među- } \\
\text { sobnog povjerenja. }\end{array}$ & 52 & 0 & 3.71 & 4 & 3 & 1.016 & 1 & 5 \\
\hline $\begin{array}{c}\text { Nadređeni često } \\
\text { uvažavaju mišljenja } \\
\text { i savjete svojih za- } \\
\text { poslenika. }\end{array}$ & 52 & 0 & 3.90 & 4 & 4 & 0.891 & 1 & 5 \\
\hline \begin{tabular}{|c}
$\begin{array}{c}\text { Primanje novčanih } \\
\text { poticaje za svoj rad } \\
\text { (povišice). }\end{array}$ \\
\end{tabular} & 52 & 0 & 3.94 & 4 & 4 & 0.998 & 1 & 5 \\
\hline $\begin{array}{c}\text { Obilježavamo razli- } \\
\text { čitih obljetnica }\end{array}$ & 52 & 0 & 3.98 & 4 & 5 & 1.260 & 1 & 5 \\
\hline $\begin{array}{l}\text { Često dobivanje } \\
\text { pohvala za dobro } \\
\text { odrađene poslove. }\end{array}$ & 52 & 0 & 4.17 & 4 & 4 & 0.834 & 1 & 5 \\
\hline $\begin{array}{c}\text { Poduzeće organizira } \\
\text { „team building“ }\end{array}$ & 52 & 0 & 4.19 & 5 & 5 & 1.011 & 1 & 5 \\
\hline $\begin{array}{c}\text { Nadređeni imaju } \\
\text { potpuno povjerenje } \\
\text { u svoje zaposlenike. }\end{array}$ & 52 & 0 & 4.23 & 4 & 5 & 0.921 & 1 & 5 \\
\hline
\end{tabular}




\begin{tabular}{|c|c|c|c|c|c|c|c|c|}
\hline $\begin{array}{l}\text { Nadređeni se na } \\
\text { različite načine tru- } \\
\text { de motivirati svoje } \\
\text { zaposlenike. }\end{array}$ & 52 & 0 & 4.27 & 4 & 5 & 0.952 & 1 & 5 \\
\hline $\begin{array}{l}\text { Nadređeni su strogi, } \\
\text { rijetko ili nikad ne } \\
\text { uvažavaju mišljenja } \\
\text { svojih zaposlenika i } \\
\text { isključivo oni dono- } \\
\text { se sve odluke. }\end{array}$ & 52 & 0 & 4.31 & 5 & 5 & 0.829 & 2 & 5 \\
\hline $\begin{array}{l}\text { Zaposlenici imaju } \\
\text { mogućnost napre- } \\
\text { dovanja ukoliko se } \\
\text { pokažu dobrima u } \\
\text { svom poslu. }\end{array}$ & 52 & 0 & 4.33 & 5 & 5 & 0.923 & 1 & 5 \\
\hline $\begin{array}{l}\text { Postoji međusobno } \\
\text { poštivanje bez ob- } \\
\text { zira na odjel kojem } \\
\text { pripadamo i posao } \\
\text { koji obavljamo. }\end{array}$ & 52 & 0 & 4.42 & 5 & 5 & 0.915 & 1 & 5 \\
\hline $\begin{array}{l}\text { Radni zadaci su u } \\
\text { skladu s mojim spo- } \\
\text { sobnostima. }\end{array}$ & 52 & 0 & 4.42 & 5 & 5 & 0.977 & 1 & 5 \\
\hline $\begin{array}{l}\text { Menadžeri se prema } \\
\text { zaposlenicima od- } \\
\text { nose s poštovanjem. }\end{array}$ & 52 & 0 & 4.50 & 5 & 5 & 0.874 & 1 & 5 \\
\hline $\begin{array}{l}\text { Radni zadaci su mi } \\
\text { previše složeni i če- } \\
\text { sto imam poteškoće } \\
\text { s obavljanjem istih. }\end{array}$ & 52 & 0 & 4.56 & 5 & 5 & 0.916 & 1 & 5 \\
\hline $\begin{array}{l}\text { Sve odluke donose } \\
\text { zaposlenici, nadre- } \\
\text { đeni su uglavnom } \\
\text { nezainteresirani za } \\
\text { posao i odgovor- } \\
\text { nosti. }\end{array}$ & 52 & 0 & 4.58 & 5 & 5 & 0.825 & 1 & 5 \\
\hline $\begin{array}{c}\text { U slučaju bilo } \\
\text { kakvih poteškoća } \\
\text { slobodan sam pitati } \\
\text { kolege za pomoć. }\end{array}$ & 52 & 0 & 4.73 & 5 & 5 & 0.598 & 3 & 5 \\
\hline $\begin{array}{l}\text { Prema novozapo- } \\
\text { slenim kolegama se } \\
\text { odnosimo prijatelj- } \\
\text { ski i s poštovanjem. }\end{array}$ & 52 & 0 & 4.81 & 5 & 5 & 0.487 & 3 & 5 \\
\hline $\begin{array}{c}\text { ORGANIZAC. } \\
\text { KULTURA }\end{array}$ & 52 & $\mathbf{0}$ & 3.97 & 4 & 4.17 & 0.489 & 2.48 & 4.70 \\
\hline
\end{tabular}

Izvor: Izrada autora prema SPSS programu 
Iz tablice 5. vidi se da je najmanju prosječnu ocjenu $(2,29)$ dobilo načelo ,mogućnost obavljanja složenijih radnih zadataka“, što znači da ispitanici smatraju da su njihove radne mogućnosti podcijenjene. Prema prethodno spomenutim razinama implementiranosti zaključuje se da je ovo načelo niže implementirano kod anketiranih poduzeća. S druge strane, ostala 22 načela organizacijske kulture imaju pojedinačne prosječne ocjene veće od 2,5 što ih svrstava u višu razinu implementiranosti kod anketiranih poduzeća. Bitno je naglasiti da je najboljom prosječnom ocjenom $(4,81)$ ocijenjena tvrdnja ,prema novozaposlenim kolegama se odnosimo prijateljski i s poštovanjem“. Kada se temeljem metode aritmetičke sredine aritmetičkih sredina pojedinačnih prosječnih ocjena 23 načela organizacijske kulture izračuna ukupni prosjek dobije se ukupna prosječna ocjena svih načela organizacijske kulture anketiranih poduzeća koja iznosi 3,97. Iz ovako dobivenog rezultata može se zaključiti da u anketiranim poduzećima postoji visoka razina implementiranosti načela organizacijske kulture.

U nastavku rada se također metodama deskriptivne statistike analiziraju odgovori ispitanika koji se odnose na faktore koji utječu na rast motivacije zaposlenika kod anketiranih poduzeća. Budući da je doprinos svakog pojedinog faktora na motivaciju zaposlenika također vrednovan s ocjenama od 1 do 5 , utvrdit će se manji i veći doprinos svakog faktora rastu motivacije zaposlenika. Ako faktor motivacije ima prosječnu ocjenu između 1 i 2,5, tada je njegov doprinos motivaciji zaposlenika manji, a ukoliko faktor motivacije ima prosječnu ocjenu između 2,5 i 5, tada se radi o većem doprinosu faktora rastu motivacije zaposlenika. Isti način će se primijeniti na utvrđivanje ukupnog doprinosa svih faktora na rast motivacije zaposlenika kod anketiranih poduzeća. Stoga je u tablici 6. prikazan doprinos 13 faktora na rast motivacije vrednovanih s prethodno spomenutih 5 stupnjeva.

S druge strane, faktor motivacije koji najmanje doprinosi rastu motivacije zaposlenika je ugled poduzeća u javnosti $(3,58)$ te ga slijede faktori poput mogućnosti stalnog učenja $(3,83)$, sudjelovanja u odlučivanju $(3,90)$ i mogućnosti preuzimanja dodatnih odgovornosti $(3,98)$. 
Tablica 6. Deskriptivna statistika faktora koji utječu na motivaciju

\begin{tabular}{|c|c|c|c|c|c|c|c|c|}
\hline \multirow[b]{2}{*}{ Faktori motivacije } & \multicolumn{2}{|c|}{$\mathbf{N}$} & \multirow[b]{2}{*}{$\begin{array}{l}\text { Ar. } \\
\text { sredina }\end{array}$} & \multirow[b]{2}{*}{$\begin{array}{c}\text { Medi- } \\
\text { jan }\end{array}$} & \multirow[b]{2}{*}{ Mod } & \multirow[b]{2}{*}{$\begin{array}{l}\text { St. } \\
\text { Dev. }\end{array}$} & \multirow[b]{2}{*}{ Min } & \multirow[b]{2}{*}{$\operatorname{Max}$} \\
\hline & $\begin{array}{c}\text { Valja- } \\
\text { no }\end{array}$ & $\begin{array}{l}\text { Nedo- } \\
\text { staje }\end{array}$ & & & & & & \\
\hline $\begin{array}{c}\text { Ugled poduzeća u } \\
\text { javnosti }\end{array}$ & 52 & 0 & 3.58 & 4 & 5 & 1.348 & 1 & 5 \\
\hline $\begin{array}{c}\text { Mogućnost stalnog } \\
\text { učenja }\end{array}$ & 52 & 0 & 3.83 & 4 & 4 & 1.115 & 1 & 5 \\
\hline $\begin{array}{c}\text { Sudjelovanje u odlu- } \\
\text { čivanju }\end{array}$ & 52 & 0 & 3.90 & 4 & 4 & 0.846 & 1 & 5 \\
\hline $\begin{array}{l}\text { Mogućnost preu- } \\
\text { zimanja dodatnih } \\
\text { odgovornosti }\end{array}$ & 52 & 0 & 3.98 & 4 & 4 & 0.804 & 2 & 5 \\
\hline $\begin{array}{l}\text { Odgovornost za iz- } \\
\text { vršene zadatke }\end{array}$ & 52 & 0 & 4.19 & 4 & 4 & 0.742 & 2 & 5 \\
\hline Nagrade i pohvale & 52 & 0 & 4.29 & 4 & 5 & 0.750 & 2 & 5 \\
\hline Zanimljivost posla & 52 & 0 & 4.33 & 4 & 4 & 0.706 & 2 & 5 \\
\hline Visina plaće & 52 & 0 & 4.38 & 4 & 4 & 0.631 & 3 & 5 \\
\hline Međuljudski odnosi & 52 & 0 & 4.42 & 5 & 5 & 0.776 & 2 & 5 \\
\hline $\begin{array}{l}\text { Mogućnost napredo- } \\
\text { vanja }\end{array}$ & 52 & 0 & 4.52 & 5 & 5 & 0.754 & 2 & 5 \\
\hline Uvjeti rada & 52 & 0 & 4.54 & 5 & 5 & 0.670 & 3 & 5 \\
\hline Sigurnost posla & 52 & 0 & 4.65 & 5 & 5 & 0.814 & 1 & 5 \\
\hline $\begin{array}{c}\text { Pravednost na rad- } \\
\text { nom mjestu (od stra- } \\
\text { ne nadređenih) }\end{array}$ & 52 & 0 & 4.75 & 5 & 5 & 0.519 & 3 & 5 \\
\hline MOTIVACIJA & 52 & $\mathbf{0}$ & 4.26 & 4.38 & 4.38 & 0.465 & 3.08 & 5 \\
\hline
\end{tabular}

Izvor: Izrada autora prema SPSS programu

Prema tablici 6. faktor motivacije s najvećom prosječnom ocjenom $(4,75)$ koji najviše doprinosi rastu motivacije zaposlenika je pravednost na radnom mjestu od strane nadređenih, a zatim slijede sigurnost posla $(4,65)$, uvjeti rada $(4,54) \mathrm{i}$ mogućnost napredovanja $(4,52)$. Bitno je naglasiti da se dobivene prosječne ocjene pojedinih 13 faktora koji utječu na rast motivacije nalaze iznad 2,5 što znači da svi navedeni faktori imaju veliki doprinos na rast motivacije zaposlenika. Kada se metoda aritmetičke sredine aritmetičkih sredina primijeni na prosječne ocjene pojedinih faktora motivacije zaposlenika, dobije se njihov ukupni doprinos na rast motivacije zaposlenika koji iznosi 4,26. Iz ovako dobivenog rezultata može se zaključiti da kod anketiranih poduzeća postoji veliki doprinos svih 13 faktora na rast motivacije zaposlenika i da se oni uvelike primjenjuju kod anketiranih poduzeća. 


\subsection{Testiranje istraživačkih hipoteza}

Temeljem prikupljenih podataka metodom anketnog upitnika testirat će se temeljna istraživačka hipoteza rada koristeći metodu korelacije, točnije Spearmanov koeficijent korelacije. Obradom prikupljenih podataka dat će se odgovor na postavljenu temeljnu istraživačku hipotezu rada koja glasi:

H1. Viša razina implementiranosti načela organizacijske kulture različito utječe na povećanje motivacije zaposlenika u djelatnosti osiguranja Splitsko-dalmatinske županije.

Temeljna istraživačka hipoteza rada ispitat će se pomoću tri pomoćne hipoteze, $i$ to:

H.1.1. Viša razina implementiranosti načela organizacijske kulture različito utječe na povećanje motivacije između menadžera i ostalih zaposlenika u djelatnosti osiguranja Splitsko-dalmatinske županije.

U testiranju ove hipoteze polazi se od pretpostavke da viša razina implementiranosti načela organizacijske kulture manje utječe na povećanje motivacije menadžera nego kod ostalih zaposlenika u djelatnosti osiguranja Splitsko-dalmatinske županije.

H.1.2. Viša razina implementiranosti načela organizacijske kulture različito utječe na povećanje motivacije zaposlenika između organizacijskih odjela u djelatnosti osiguranja Splitsko-dalmatinske županije.

U testiranju ove hipoteze polazi se od pretpostavke da viša razina implementiranosti načela organizacijske kulture manje utječe na povećanje motivacije zaposlenika u odjelu prodaje i pribave nego u ostalim odjelima u djelatnosti osiguranja Splitsko-dalmatinske županije.

H1.3. Viša razina implementiranosti načela organizacijske kulture različito utječe na povećanje motivacije muškaraca $i$ žena zaposlenih u djelatnosti osiguranja Splitsko-dalmatinske županije.

U testiranju ove hipoteze polazi se od pretpostavke da viša razina implementiranosti načela organizacijske strukture više utječe na povećanje motivacije muškaraca nego žena zaposlenih u djelatnosti osiguranja Splitsko-dalmatinske županije. 
Budući da se temeljna istraživačka hipoteza rada ispituje pomoću tri pomoćne hipoteze rada, u nastavku rada najprije će se prikazati rezultati istraživanja za prvu pomoćnu hipotezu rada koji su prikazani u tablici 7.

Tablica 7. Korelacija između razine implementiranosti načela organizacijske kulture i motivacije za menadžere i ostale zaposlenike u djelatnosti osiguranja Splitsko-dalmatinske županije

\begin{tabular}{|c|c|c|}
\hline RAZINA IMPLEMENTIRANOSTI & \multicolumn{2}{|c|}{ MOTIVACIJA } \\
\cline { 2 - 3 } NAČELA ORGANIZACIJSKE KULTURE & Menadžeri & Ostali zaposlenici \\
\hline Koeficijent korelacije (r) & 0.154 & $0,453^{*}$ \\
\hline p- vrijednost & 0.482 & 0,014
\end{tabular}

*Korelacija je signifikantna (značajna) na razini 0,05 .

Izvor: Izrada autora prema SPSS programu

Kao što prikazuje tablica 7. dobiveni koeficijent korelacije $(\mathrm{r}=0.154)$ pokazuje da između razine implementiranosti načela organizacijske kulture i motivacije kod menadžera u djelatnosti osiguranja Splitsko-dalmatinske županije postoji slaba i pozitivna veza koja nije statistički značajna $(p=0,482 ; p>0,05)$. Ovako dobiveni rezultati istraživanja pokazuju viša razina implementiranosti načela organizacijske kulture slabo uzrokuje povećanje motivacije kod menadžera u djelatnosti osiguranja u Splitsko-dalmatinskoj županiji, ali bez statističke značajnosti. S druge strane, $\mathrm{u}$ istoj tablici dobiveni koeficijent korelacije $(\mathrm{r}=0.453$ ) pokazuje da između razine implementiranosti načela organizacijske kulture i motivacije kod ostalih zaposlenika u djelatnosti osiguranja Splitsko-dalmatinske županije postoji srednje jaka, pozitivna i statistički značajna veza $(p=0,014 ; p<0,05)$. Ovako dobiveni rezultati istraživanja pokazuju da viša razina implementiranosti načela organizacijske kulture uzrokuje srednje jako povećanje motivacije kod ostalih zaposlenika koje je statistički značajno. S obzirom da su rezultati istraživanja pokazali različiti statistički utjecaj više razine implementiranosti načela organizacijske kulture na povećanje motivacije kod menadžera i ostalih zaposlenika u djelatnosti osiguranja Splitsko-dalmatinske županije, prva pomoćna hipoteza (H1.1.) se prihvaća.

Za testiranje druge pomoćne hipoteze također je korištena metoda korelacije između više razine implementiranosti načela organizacijske kulture i motivacije zaposlenika između odjela prodaje i pribave i ostalih odjela kod anketiranih poduzeća. Rezultati provedenog istraživanja prikazani su u tablici 8. 
Tablica 8. Korelacija između razine implementiranosti načela organizacijske kulture i motivacije u odjelu prodaje i pribave te ostalim odjelima u djelatnosti osiguranja Splitsko-dalmatinske županije

\begin{tabular}{|c|c|c|}
\hline \multirow{2}{*}{$\begin{array}{l}\text { RAZINA IMPLEMENTIRANOSTI NAČELA } \\
\text { ORGANIZACIJSKE KULTURE }\end{array}$} & \multicolumn{2}{|c|}{ MOTIVACIJA } \\
\hline & $\begin{array}{c}\text { Odjel prodaje } \\
\text { i pribave }\end{array}$ & Ostali odjeli \\
\hline Koeficijent korelacije (r) & 0.199 & 0.216 \\
\hline $\mathrm{p}$ - vrijednost & 0.401 & 0.439 \\
\hline
\end{tabular}

*Korelacija je signifikantna (značajna) na razini 0,05 .

Izvor: Izrada autora prema SPSS programu

Kao što je vidljivo iz tablice 8 . dobiveni koeficijent korelacije između razine implementiranosti načela organizacijske kulture i motivacije u odjelu prodaje i pribave u djelatnosti osiguranja Splitsko-dalmatinske županije je r = 0,199 uz statističku značajnost testa od $\mathrm{p}=0,401(\mathrm{p}>0,05)$. Ovako dobiveni rezultati istraživanja pokazuju postojanost slabe i pozitivne vezu koja nije statistički značajna. Stoga se može zaključiti da viša razina implementiranosti načela organizacijske kulture slabo utječe na povećanje motivacije u odjelu prodaje i probave $u$ djelatnosti osiguranja Splitsko-dalmatinske županije, ali bez statističke značajnosti. S druge strane, $\mathrm{u}$ istoj tablici dobiveni koeficijent korelacije između razine implementiranosti načela organizacijske kulture i motivacije u ostalim odjelima u djelatnosti osiguranja Splitsko-dalmatinske županije je $\mathrm{r}=0,216$ uz statističku značajnost testa od p $=0,439(\mathrm{p}>0,05)$. Ovako dobiveni rezultati istraživanja pokazuju da viša razina implementiranosti načela organizacijske kulture srednje jako utječe na povećanje motivacije u ostalim odjelima što nije statistički značajno. S obzirom da su rezultati istraživanja pokazali isti statistički utjecaj više razine implementiranosti načela organizacijske kulture na motivaciju između odjela prodaje i pribave i ostalih odjela u djelatnosti osiguranja Splitsko-dalmatinske županije, druga pomoćna hipoteza (H1.2.) se ne prihvaća.

Kao i kod prethodnih pomoćnih hipoteza, za testiranje treće pomoćne hipoteze korištena je metoda korelacije između razine implementiranosti načela organizacijske kulture i rasta motivacije kod muškaraca i žena u djelatnosti osiguranja Splitsko-dalmatinske županije. Rezultati provedenog istraživanja prikazani su u tablici 9. 
Tablica 9. Korelacija između razine implementiranosti načela organizacijske kulture i motivacije muškaraca i žena u djelatnosti osiguranja Splitsko-dalmatinske županije

\begin{tabular}{|c|c|c|}
\hline RAZINA IMPLEMENTIRANOSTI NAČELA & \multicolumn{2}{|c|}{ MOTIVACIJA } \\
\cline { 2 - 3 } ORGANIZACIJSKE KULTURE & Muškarci & Žene \\
\hline Koeficijent korelacije (r) & $0.565^{*}$ & -0.027 \\
\hline $\begin{array}{c}\text { p- vrijednost } \\
\text { *Korelacija je signifikantna (značajna) na razini } 0,05\end{array}$ & 0.900 \\
\end{tabular}

*Korelacija je signifikantna (značajna) na razini 0,05 .

Izvor: Izrada autora prema SPSS programu

Iz tablice 9. vidi se dobiveni koeficijent korelacije $(r=0.565)$ pokazuje da između razine implementiranosti načela organizacijske kulture i motivacije kod muškaraca u djelatnosti osiguranja Splitsko-dalmatinske županije postoji srednje jaka i pozitivna veza koja je statistički značajna ( $p=0,002 ; p<0,05)$. Ovako dobiveni rezultati istraživanja pokazuju viša razina implementiranosti načela organizacijske kulture srednje jako uzrokuje povećanje motivacije kod muškaraca u djelatnosti osiguranja u Splitsko-dalmatinskoj županiji uz postojanje statističke značajnosti. S druge strane, u istoj tablici dobiveni koeficijent korelacije ( $\mathrm{r}=$ - 0.027) pokazuje da između razine implementiranosti načela organizacijske kulture i motivacije kod ostalih zaposlenika u djelatnosti osiguranja Splitsko-dalmatinske županije postoji slaba i negativna veza koja nije statistički značajna ( $\mathrm{p}=$ $0.900 ; p>0,05)$. Ovako dobiveni rezultati istraživanja pokazuju da viša razina implementiranosti načela organizacijske kulture uzrokuje smanjenje motivacije kod žena što nije statistički značajno. S obzirom da su rezultati istraživanja pokazali različiti statistički utjecaj više razine implementiranosti načela organizacijske kulture na povećanje motivacije kod muškaraca i žena u djelatnosti osiguranja Splitsko-dalmatinske županije, treća pomoćna hipoteza (H1.3.) se prihvaća.

Testiranjem pomoćnih hipoteza utvrđeno je da se prva (H1.1.) i treća (H.1.3.) pomoćna hipoteza prihvaćaju, dok se druga (H.1.2.) pomoćna hipoteza ne prihvaća. Slijedom prethodno navedenog, može se zaključiti da se temeljna istraživačka hipoteza rada (H1.) djelomično prihvaća.

\section{ZAKLJUČAK}

Različiti autori definiraju pojam organizacijske kulture na različit način te stoga da nema jedinstvene definicije organizacijske kulture. No, jedno je sigurno. Uz sve navedene elemente organizacijske kulture, nedvojbena je njena važnost u poduzeću. Poduzeća koja njeguju svoju organizacijsku kulturu, koja je nastoje razumjeti, uspostaviti i održavati, brže ostvaruju svoje ciljeve te teže konstantom rastu i razvoju. Budući da poslovni svijet iz dana u dan postaje sve turbulentniji i sve je teže predvidjeti situaciju na tržištu, poduzeća koja razvijaju snažnu organizacijsku kulturu sposobnija su se prilagoditi promjenjivim zahtjevima na 
tržištu. Ključnu ulogu u procesu uspostavljanja organizacijske kulture unutar jednog poduzeća imaju menadžeri. Oni predstavljaju „stup“ poduzeća. Svoju snagu dužni su prikazati kroz strpljivost, upornost i razumijevanje, osobito kad nastupe situacije u kojima je nužna promjena organizacijske kulture. Promjena organizacijske kulture ujedno znači i promjenu stavova, uvjerenja i mišljenja zaposlenika te organizacije. Da bi provedba tih promjena bila uspješna, nužno je da sami menadžeri prihvate te promjene. Posljedica uvođenja tih promjena najviše se ogleda na djelovanju i motivaciji zaposlenika.

U ovom radu obuhvaćeno je i pitanje motivacije zaposlenika. Baš kao što nema jedinstvene definicije organizacijske kulture, tako su mišljenja autora podijeljena i kada je riječ o motivaciji. Radni učinak pojedinca ne ovisi samo o njegovim stručnim sposobnostima i kompetencijama. U velikoj mjeri, dobrom radnom učinku doprinosi i motivacija pojedinca. Stoga se postavlja pitanje što je to zbog čega bi se zaposlenik osjećao motiviranim da na radnom mjestu da svoj maksimum. Ovo je pitanje koje dijeli mišljenja mnogih autora. Jedni tvrde da se motivacija veže isključivo za ljudske potrebe koje imaju svi pojedinci, dok drugi, pak, tvrde da se motivacija promatra kroz kognitivne procese koje određuju ljudsko ponašanje. Iako svakoj osobi, tj. svakom zaposleniku treba pristupiti pojedinačno kako bi se njegove potrebe najbolje razumjele, ipak postoje neki faktori motivacije koji se mogu smatrati zajedničkim za sve ljude.

U ovom radu postavlja se pitanje povezanosti razine implementacije načela organizacijske kulture i motivacije u djelatnosti osiguranja Splitsko-dalmatinske županije. Neosporna je činjenica da su zaposlenici poduzeća koja imaju snažnu organizacijsku kulturu zadovoljniji, a samim time i više motivirani. Stoga, rad istražuje postojanje različitog utjecaja više razine implementiranosti načela organizacijske kulture na povećanje motivacije u djelatnosti osiguranja Splitsko-dalmatinske županije. Statističkom obradom prikupljenih podataka utvrđeno je da se temeljna hipoteza rada djelomično prihvaća, odnosno da postoji različitost utjecaja više razine implementacije načela organizacijske kulture na motivaciju zaposlenika s obzirom na spol i poziciju zaposlenika kod poduzeća u djelatnosti osiguranja Splitsko-dalmatinske, dok prema pripadnosti organizacijskim odjelima ne postoji.

Prilikom provođenja istraživanja za potrebe ovog rada postojala su dva bitna ograničenja. Prvo ograničenja se odnosi na veličinu uzorka koju bi u budućim istraživanjima trebalo proširiti ukoliko se želi postići još jače postojanje korelacijske veze i statističke značajnosti testa između postavljenih istraživačkih varijabli. Bitno je naglasiti da veličina uzorka, koja je primijenjena u ovom radu, itekako primjerena s obzirom na postojanje nedovoljne važnosti primjene načela organizacijske kulture u poslovanju kod anketiranih poduzeća u djelatnosti 
osiguranja Splitsko-dalmatinske županije i s obzirom na veličinu uzorka koja je prikazana u prethodno navedenim istraživanjima. Drugo ograničenje rada odnosi se na postojanje neusklađenosti između navedenih načela organizacijske kulture u anketnom upitniku i njihovog stvarnog pojmovnog određivanja kod anketiranih poduzeća. Razlog navođenja ovog ograničenja je što je tijekom provođenja istraživanja anketnim upitnikom postojala stalna potreba pojmovnog objašnjenja navedenih načela anketiranim poduzećima kako bi se dobila visoka razina adekvatnosti odgovora.

Uz prethodno navedena ograničenja istraživanja, autori također predlažu preporuke za buduća istraživanja. Ovaj koncept istraživanja je moguće proširiti na cjelokupno područje Republike Hrvatske gdje je, uz postojeće istraživačke smjernice, moguće napraviti komparativnu analizu između županija. Uz to, ovo istraživanje je moguće provesti unutar drugih industrija i identificirati istraživačke rezultate kod istih te utvrditi: kakva je razina implementacije načela organizacijske kulture kod pojedinih oblika organizacijske strukture i kod kojih oblika organizacijske strukture postoji jača korelacijska veza i statistička značajnost s obzirom na motivaciju ili efikasnosti poslovanja.

\section{LITERATURA}

1. Bahtijarević - Šiber, F. (1991.). Organizacijska kultura: operacionalizacija $i$ istraživanje. Zagreb: Ekonomski fakultet.

2. Bahtijarević - Šiber, F. (1996.). Zadaci menadžmenta u motiviranju zaposlenih. Zagreb: Slobodno poduzetništvo.

3. Bahtijarević-Šiber F., et.al. (1991.). Organizacijska kultura. Zagreb: Informator.

4. Belak S., Ušljebrka, I. (2014.). Organizacijska kultura kao čimbenik uspješne provedbe organizacijske promjene, Oeconomica Jadertina, 4 (2), 80-89

5. Bogdanović, M. (2003.). Dijagnosticiranje organizacijske klime, Ekonomski pregled, 54 (9-10), 829-856.

6. Brnad, A. et al. (2016.). Istraživanje motivacije i zadovoljstva zaposlenika u Republici Hrvatskoj, Zbornik Veleučilišta u Rijeci, 4 (1), 109-122

7. Copuš, L., et. al. (2019.). Organizational culture and its Motivational Potential in Manufacturing Industry: Subculture Perspeltive, Procedia Manufacturing, 32 (1), 360-367

8. Cucu-Ciuhan, G., Guita-Alexandru, I. (2014.). Organizational culture versus motivation for the academic staff in a public university, Procedia-Social nad Behavioral Sciences, 127 (1), 448-453 
9. Danish, R. Q. (2010.). Impact of Reward and Recognition on Job Satisfaction and Motivation: An Empirical Study from Pakistan, International Journal od Business and Management, 5(2), 159-167

10. Denison D. R., Mishra, A. K. (1995.). Toward a Theory of Organizational Culture and Effectiveness, Organization Science, 6 (2), 204-223

11. Dulčić, Ž., Vrdoljak - Raguž, I. (2007.). Stilovi vodstva hotelskih menadžera Dubrovačko-neretvanske županije - empirijsko istraživanje, Ekonomski pregled, 58 (11), 709-731

12. Kurtić, A., Kulović, Dž. (2011.). Poslovno vođenje, Sarajevo: JORDAN Studio.

13. Marušić, S. (2006.). Upravljanje ljudskim potencijalima, 4. izmijenjeno i dopunjeno izdanje. Zagreb: ADECO.

14. Panagotis, M., et. al. (2014.). Organizational Culture and Motovation in the Public Sector. The case of the City of Zografou, Procedia Economics and Finance, 14 (1), 415-424

15. Robbins, S. P. (1996.). Bitni elementi organizacijskog ponašanja, 3. izdanje, Zagreb: MATE d.o.o.

16. Schein, E. H. (2010.). Organizational Culture and Leadership, $4^{\text {th }}$ Edition. San Francisco Jossey Bass.

17. Štok - Meško, Z., et al.(2010.). Elements of organizational culture leading to business excellence, Zbornik radova Ekonomskog fakulteta u Rijeci, Vol 28 (2), 303-318

18. Tudor, G.; Rijavec, M.; Zarevski, P. (2009.). Menadžerska učinkovitost 360: dobar menadžer sam sebi, drugo izdanje. Zagreb: M.E.P. d.o.o..

19. Uzonna U. R. (2013.). Impact of motivation on employees' performance: A case study of CreditWest Bank Cyprus, Journal of Economics and International Finance, 5(5), 199-211

20. Varga, M. (2011.). Upravljanje ljudskim potencijalima kroz motivaciju, Zbornik radova Međimurskog veleučilišta u Čakovcu, 2 (1), 152-169

21. Zdrilić, I., Puvača, M., Roso, D. (2010.). Utjecaj globalizacije na promjene u načinu poslovanja i organizacijskoj kulturi, Ekonomski Vjesnik, 23 (2), 503-513

22. Žugaj, M., Cingula, M.(1992.). Temelji organizacije. Varaždin: FOING.

23. Žugaj, M. et al. (2004.). Organizacijska kultura u funkciji uspješnosti poslovanja organizacije, Ekonomski vjesnik broj, 17 (1-2), 17-29 
Željko Mateljak, PhD

University of Split, Faculty of Economics, Business and Tourism, Split, Croatia zeljko.mateljak@efst.hr

Maja Kraljević, student

University of Split, Faculty of Economics, Business and Tourism, Split, Croatia mkralj02@live.efst.hr

\title{
LEVEL OF IMPLEMENTATION OF ORGANIZATIONAL CULTURE'S PRINCIPLES AND ITS IMPACT ON THE EMPLOYEES MOTIVATION IN THE INSURANCE BUSINESS IN THE SPLIT- DALMATIA COUNTY
}

Received: November 30, 2020

Accepted: December 23, 2020

https://doi.org/10.46458/27121097.2020.26.85

Preliminary communication

\begin{abstract}
In today's increasingly complex business environment, it is necessary to have a high level of implementation of organizational culture in the company with which it will successfully respond to market demands. In the implementation of organizational culture, the effective implementation of the basic principles plays the most important role and its bearers are the employees, which makes them more and more satisfied and motivated in achieving the set goals of the company. Therefore, the aim of this paper is to identify how the level of implementation of organizational culture's principles affects the motivation of employees in the insurance business of the Split-Dalmatia County. The basic hypothesis of the paper examines the impact of a higher level of implementation of the organizational culture's principles on the greater motivation of employees in the insurance industry of the Split-Dalmatia County with regard to gender and position of employees and their affiliation to organizational departments. The research conducted by statistical processing of data collected by the questionnaire showed that there is a difference in the higher level of implementation of the organizational culture's principles on the motivation of county employees with regard to gender and position of employees in insurance companies in the Split-Dalmatia, while according to organizational departments that does not exist.
\end{abstract}

Keywords: organizational culture, motivation, insurance business, managers, other employees;

JEL: L2 